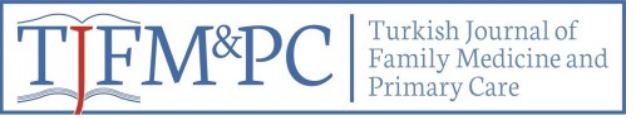

\title{
Evaluation of Drug Reports Issued in a Family Practice Unit
}

Bir Aile Hekimliği Biriminde Düzenlenen İlaç Raporlarının
Değerlendirilmesi

\author{
Onur Öztürk ${ }^{* 1}$, Mustafa Ünal ${ }^{2}$, Muhammet Ali Oruç ${ }^{3}$, Mikail Özdemir ${ }^{4}$
}

\begin{abstract}
Objectives: In this study, it was aimed to evaluate the drug reports prepared by a family medicine specialist who had worked in a family practice unit more than four years. Methods: This study, in which a retrospective archive review was conducted, was carried out in a unit of a family healthcare center in Asarcik district of Samsun. The owners of the drug reports issued in that unit between August 2015 and October 2019 constitutes the sample. Results: A total of 623 reports of 446 individuals whose drug reports had been renewed or issued for the first time were evaluated. The average age was $61.81 \pm 16.24$, and an average of 2.19 reports per patient was prepared. At least one antihypertensive drug report was prepared for $79.37 \%(n=354)$ of the patients, and at least one oral antidiabetic drug report was prepared for $14.57 \%(n=65)$. Diuretics $(n=225,50.45 \%)$ were the most common among antihypertensives drugs, and metformin $(\mathrm{n}=54,12.11 \%)$ was the most common among oral antidiabetics. Drugs evaluated in cardiovascular system were the most frequently reported with $1.55 \pm 1.10$ times per report. Compared to age, the number of drugs used in cardiovascular system disorders shows a positive and weak correlation $(p<0.001, r=0.266)$. Conclusion: It has been observed that the primary care specialist has an active role in the medical follow-up of chronic diseases by the drug reports. Therefore, it may be beneficial to increase the variety of issuable drugs reports.
\end{abstract}

Key words: Family practice, drug, report, chronic disease

\section{ÖZET}

Amaç: Bu çalışmada bir aile hekimliği biriminde dört yıldan uzun süre çalışan bir aile hekimliği uzmanının düzenlediği ilaç raporlarının değerlendirilmesi amaçlanmıştır. Gereç ve Yöntem: Retrospektif arşiv incelemesinin yapıldığı bu çalışma Samsun iline bağlı Asarcık ilçesinde bir aile sağlığı merkezine bağlı birimde gerçekleştirilmiştir. Ağustos 2015- Ekim 2019 tarihleri arasında ilgili birimde düzenlenen ilaç raporlarının sahipleri örneklemi oluşturmaktadır. Bulgular: İlaç raporu yenilenen veya ilk defa düzenlenen 446 kișinin 623 adet raporu incelenmiștir. Yaș ortalaması $61,81 \pm 16,24$ olup, hasta bașına ortalama 2,19 kez rapor düzenlenmiştir. Hastaların \%79,37'ine $(n=354)$ en az bir adet antihipertansif ilaç raporu düzenlenmiştir, \%14,57'sine $(n=65)$ ise en az bir adet oral antidiyabetik ilaç raporu düzenlenmiştir. Antihipertansif ilaçlardan en sık diüretikler $(\mathrm{n}=225, \% 50,45)$, oral antidiyabetik ilaçlardan en sık

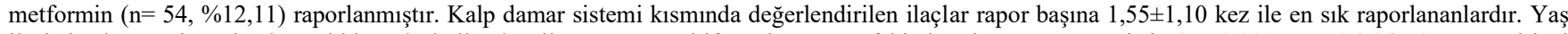
ile kalp damar sistemi rahatsızlıklarında kullanılan ilaç sayısı pozitif yönlü ve zayıf bir korelasyon göstermiștir ( $p<0,001, r=0,266$ ). Sonuç: Birinci basamak uzmanının kronik hastalıklarının medikal izleminde düzenlediği raporlarla etkin rol aldığı görülmüştür. Bu yüzden, düzenlenebilen ilaç raporu çeşitliliğinin artması faydalı olabilir.

Anahtar kelimeler: Aile hekimliği, ilaç, rapor, kronik hastalık

Received / Geliş tarihi: 25.09.2020, Accepted / Kabul tarihi: 09.11.2020

${ }^{1}$ SBU Samsun Eğitim ve Araştırma Hastanesi, Aile Hekimliği Kliniği, Samsun-TÜRKIYE.

${ }^{2}$ Ondokuz Mayıs Üniversitesi Tıp Fakültesi, Aile Hekimliği Departmanı, Samsun-TÜRKIYE.

${ }^{3}$ Ahi Evran Üniversitesi Tıp Fakültesi, Aile Hekimliği Departmanı, Kırşehir-TÜRKIYE.

${ }^{4}$ Osmaniye Merkez Toplum Sağlığı Merkezi, Osmaniye-TÜRKIYE.

*Address for Correspondence / Yazışma Adresi: Onur Öztürk, SBU Samsun Eğitim ve Araştırma Hastanesi, Aile Hekimliği Kliniği, SamsunTÜRKIYE.

E-mail: dr.onurozturk@yahoo.com

Öztürk O, Ünal M, Oruç MA, Özdemir M. Bir Aile Hekimliği Biriminde Düzenlenen İlaç Raporlarının Değerlendirilmesi.TJFMPC, 2021;15(1):27-32.

DOI: $10.21763 /$ tjfmpc.798869 


\section{Gİiş̧}

Kronik hastalıklar günümüzde dünya genelinde hastalık yükünün büyük bir kısmını oluşturması, diğer hastalıklara ve ölüme sebebiyet vermesi ile önem taşımaktadır. Kronik hasta sayısının gün geçtikçe artması da işin başka bir boyutudur. ${ }^{1,2}$ Aile hekimliği uzmanlığı, kronik hasta takibinde birinci basamağın elinin güçlenmesi ve hastanın ikinci ve üçüncü basamağ1 tercih etmesinin önlenebilmesi adına gerekli bir uzmanlık dalıdır. Birinci basamakta çalışan aile hekimliği uzmanları, uzmanlık eğitimlerini birinci basamak sağlık hizmeti sunabilmek üzerine tamamlamış, gerekli durumlarda ilaç raporu düzenleme yetkisine sahip hekim grubudur.

$\mathrm{Bu}$ çalışmada bir aile hekimliği biriminde dört yıldan uzun süre çalışan bir aile heklimliği uzmanının düzenlediği ilaç raporları irdelenmiş, kronik hastalık yönetimi medikasyon bazında değerlendirilmiștir. Türkiye'de birinci basamağı ilgilendiren başka bir ilaç raporu çalışmasına ulaşılamadığı için literatüre katk1 sunulacağı düşünülmektedir.

\section{YÖNTEM}

Retrospektif arşiv incelemesinin yapıldığ 1 bu çalışma Samsun iline bağlı Asarcık ilçesinde (Şekil 1) bir aile sağlığı merkezinin 5503006 no'lu biriminde gerçekleştirilmiştir. Araştırmanın evrenini ilgili birime kayıtll, her yaş ve cinsiyetten 3500 hasta oluşturmaktadır. Örneklemi ise Ağustos 2015- Ekim 2019 tarihleri arasında ilgili birimde çalışan uzman hekimce düzenlenen ilaç raporlarının sahipleri oluşturmaktadır. Süresi dolunca tekrarlanan raporlar dahil, düzenlenen bütün ilaç raporları değerlendirmeye dahil edilmiştir. Hasta bilgilerinin gizliliği, bütünlüğü, güvenliği ve mahremiyetini deşifre edecek herhangi bir bilgi kullanılmamıştır. Veriler ilgili birimde çalışan ve aynı zamanda çalışmanın yazarları arasında yer alan uzman hekim tarafınca, kullandığı özel otomasyon sistemi arşivinde kayıtlı olan ilaç raporlarına ulaşmak suretiyle değerlendirilmiştir. Raporların sahibi hastalarınyaş, cinsiyet, tanı, ilaç içeriği ve rapor süresi kayıt edilmiştir. Verilerin analizinde SPSS sürüm 15.0 (IBM, USA) programından yararlanılmıştır. Değişkenlerin normal dağılıma uygunluğu, histogram grafikleri ve KolmogorovSmirnov testi ile incelenmiştir. Tanımlayıcı analizler sunulurken ortalama, standart sapma, ortanca ve minimum- maksimum değerler kullanılmıştır. Ölçümsel verilerin birbirleri ile kıyaslanmasında Spearman Korelasyon Testi'nden faydalanılmıştır. P-değerinin 0.05 'in altında olduğu durumlar istatistiksel olarak anlamlı sonuçlar şeklinde değerlendirilmiştir. $\mathrm{Bu}$ çalışma için Samsun İl Sağlık Müdürlüğü ile protokol düzenlenmiş, SBU Samsun Eğitim ve Araştırma Hastanesi Etik Kurulundan GOKA/2020/8/22 say1l etik onay alınmıştır.

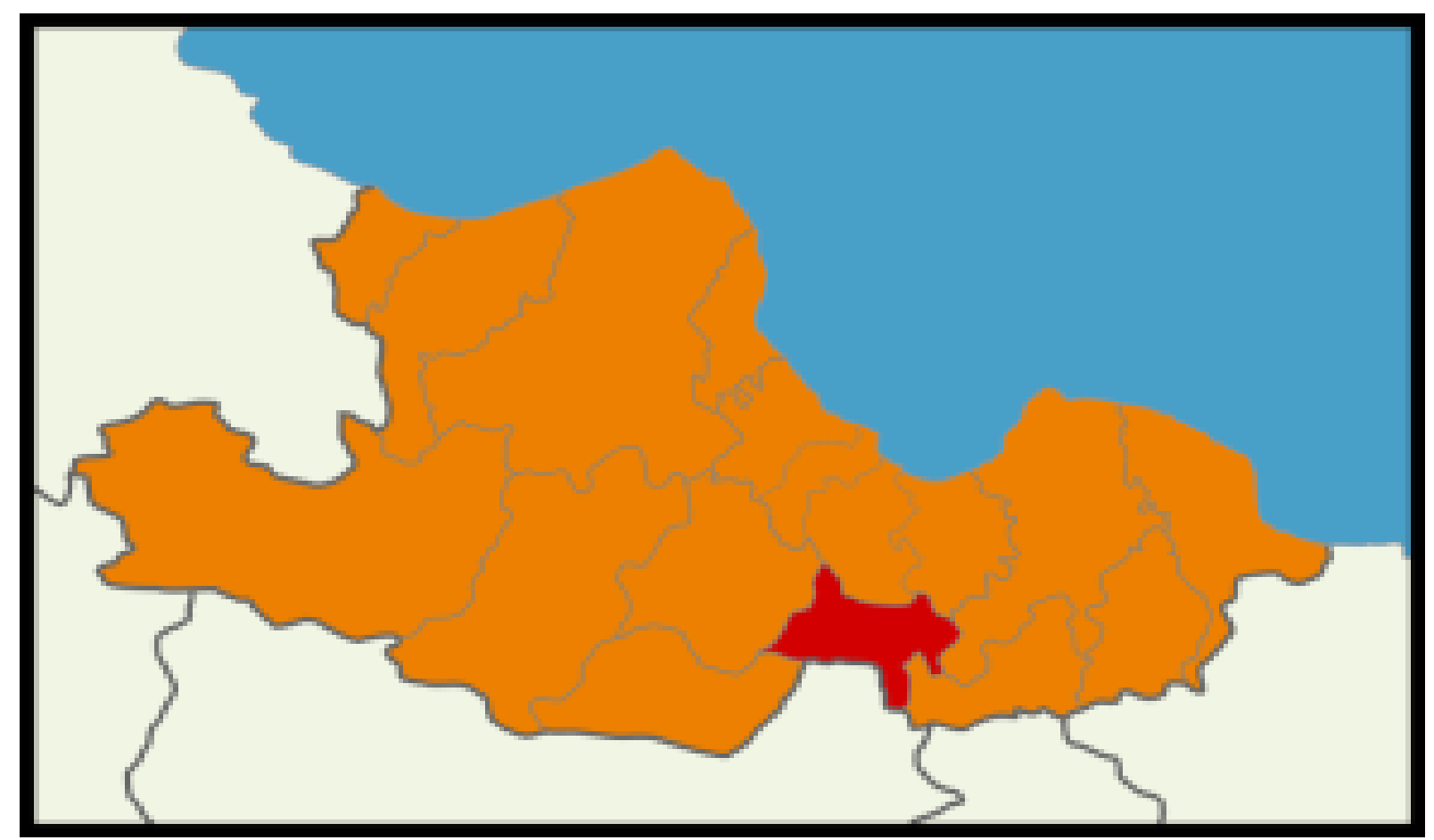

Şekil 1. Asarcık'ın Samsun içerisindeki konumu ${ }^{3}$ 


\section{BULGULAR}

İlaç raporu yenilenen veya ilk defa düzenlenen 371' i erkek (\%83,2), 75'i kadın (\%16,8) 446 kişinin 623 adet raporu incelenmiştir. Hastaların yaş ortalaması
$61,81 \pm 16,24$ 'dir. Etken madde, ilaç ve rapor sayısı ortalaması Tablo 1'de gösterilmiştir.

\begin{tabular}{|c|c|c|c|c|c|}
\hline & Mean & $\pm \mathrm{SS}$ & Median & Minimum & Maximum \\
\hline Rapor say1s1 & 2,19 & 1,27 & 2,00 & 1,00 & 9,00 \\
\hline Raporlanan etken madde & 2,84 & 1,92 & 2,00 & 1,00 & 14,00 \\
\hline Rapor başına ilaç sayısı & 1,35 & 0,66 & 1,00 & 1,00 & 7,00 \\
\hline
\end{tabular}

Hastaların \%79,37'ine $(n=354)$ en az bir adet antihipertansif ilaç raporu düzenlenmiştir,
$\% 14,57$ 'sine ise en az bir adet oral antidiyabetik ilaç raporu düzenlenmiştir (Tablo 2).

\begin{tabular}{|c|c|c|}
\hline & $\mathrm{n}$ & $\%$ \\
\hline Antihipertansif ilaçlar & 354 & 79,37 \\
\hline Oral antidiyabetik ilaçlar & 65 & 14,57 \\
\hline Antiagregan/ antikoagülan ilaçlar & 32 & 7,17 \\
\hline Antihiperlipidemik ilaçlar & 19 & 4,26 \\
\hline Proton pompa inhibitörü ilaçlar & 16 & 3,59 \\
\hline Diğer & 45 & 10,09 \\
\hline
\end{tabular}

\begin{tabular}{|c|c|c|c|c|c|c|c|c|c|c|c|}
\hline \multicolumn{2}{|c|}{$\begin{array}{c}\text { Anti } \\
\text { hipertansif }\end{array}$} & \multicolumn{2}{|c|}{$\begin{array}{c}\text { Oral } \\
\text { andiyabetik }\end{array}$} & \multicolumn{2}{|c|}{$\begin{array}{l}\text { Antiagregan/ } \\
\text { antikoagülan }\end{array}$} & \multicolumn{2}{|c|}{$\begin{array}{c}\text { Anti } \\
\text { hiperlipidemik }\end{array}$} & \multicolumn{2}{|c|}{$\begin{array}{l}\text { Proton pompa } \\
\text { inhibitörü }\end{array}$} & \multicolumn{2}{|c|}{ Diğer } \\
\hline Diüretik & $\begin{array}{l}\mathrm{n}=225 \\
\% 50,45\end{array}$ & Metformin & $\begin{array}{l}\mathrm{n}=54 \\
\% 12,11\end{array}$ & $\begin{array}{l}\text { Asetilsalisilik } \\
\text { asit }\end{array}$ & $\begin{array}{l}\mathrm{n}=28 \\
\% 6,28\end{array}$ & Statin & $\begin{array}{l}\mathrm{n}=14 \\
\% 3,14\end{array}$ & Rabeprazol & $\begin{array}{l}\mathrm{n}=7 \\
\% 1,57\end{array}$ & $\begin{array}{l}\text { Şeker } \\
\text { ölçüm } \\
\text { çubuğu }\end{array}$ & $\begin{array}{l}\mathrm{n}=12 \\
\% 2,68\end{array}$ \\
\hline $\begin{array}{l}\text { Angiotensin II } \\
\text { reseptör } \\
\text { blokeri }\end{array}$ & $\begin{array}{l}\mathrm{n}=186 \\
\% 41,70\end{array}$ & Gliklazid & $\begin{array}{l}\mathrm{n}=25 \\
\% 5,61\end{array}$ & Varfarin & $\begin{array}{l}\mathrm{n}=4 \\
\% 0,90\end{array}$ & Fibrat & $\begin{array}{l}\mathrm{n}=8 \\
\% 1,79\end{array}$ & Lansoprazol & $\begin{array}{l}\mathrm{n}=3 \\
\% 0,67\end{array}$ & Kolşisin & $\begin{array}{l}\mathrm{n}=11 \\
\% 2,47\end{array}$ \\
\hline $\begin{array}{l}\text { Angiotensin } \\
\text { converting } \\
\text { enzyme } \\
\text { inhibitorü } \\
\end{array}$ & $\begin{array}{l}n=110 \\
\% 24,66\end{array}$ & & & & & & & Pantoprazol & $\begin{array}{l}\mathrm{n}=3 \\
\% 0,67\end{array}$ & $\begin{array}{l}\text { Selektif } \\
\text { serotonin } \\
\text { gerialım } \\
\text { inhibitörü }\end{array}$ & $\begin{array}{l}\mathrm{n}=6 \\
\% 1,34\end{array}$ \\
\hline $\begin{array}{l}\text { Ca kanal } \\
\text { blokeri }\end{array}$ & $\begin{array}{l}\mathrm{n}=106 \\
\% 23,77\end{array}$ & & & & & & & Esameprazol & $\begin{array}{l}\mathrm{n}=3 \\
\% 0,67\end{array}$ & & \\
\hline Beta bloker & $\begin{array}{l}\mathrm{n}=32 \\
\% 7,17\end{array}$ & & & & & & & & & & \\
\hline
\end{tabular}

Antihipertansif ilaçlardan en sık diüretikler $(n=225$, $\% 50,45)$, Oral antidiyabetik ilaçlardan en s1k metformin $\quad(n=54, \% 12,11)$ antiagregan/ antikoagülan ilaçlardan en s1k asetilsalisilikasit $(\mathrm{n}=28, \% 6,28)$, antihiperlipidemik ilaçlardan en s1k statin $(n=14, \% 3,14)$, proton pompa inhibitörü ilaçlardan en s1k rabeprazol $(n=7, \% 1,57)$, diğerlerinden ise en sık şeker ölçüm çubuğu $(n=12$, $\% 2,68$ ) raporu düzenlenmiştir (Tablo 3). 
İlaçlar ilgili sistemlere göre kategorize edilince kalp damar sistemi kısmında değerlendirilen ilaçlar rapor başına $1,55 \pm 1,10 \mathrm{kez}$ ile en sik raporlananlar olmuştur (Tablo 4).

Tablo 4. İlaç raporlarının sistemlere göre kategorizasyonu
\begin{tabular}{|l|c|c|c|c|c|}
\hline & Mean & \pm ss & Median & Minimum & Maksimum \\
\hline Kalp damar sistemi & 1,55 & 1,10 & 2,00 &, 00 & 5,00 \\
\hline Sindirim sistemi ve metabolizma &, 21 &, 49 &, 00 &, 00 & 2,00 \\
\hline Sinir sistemi &, 07 &, 27 &, 00 &, 00 & 2,00 \\
\hline Kas iskelet sistemi &, 03 &, 16 &, 00 &, 00 & 1,00 \\
\hline Kan ve kan yapıc1 organlar &, 01 &, 09 &, 00 &, 00 & 1,00 \\
\hline
\end{tabular}

Yaş ile kıyaslandığında hasta başına raporlanan; kalp damar sistemi rahatsızlıklarında kullanılan ilaç sayısı pozitif yönlü ve zayıf bir korelasyon göstermiştir $(\mathrm{p}<0,001, \mathrm{r}=0,266)$ (Şekil 2).

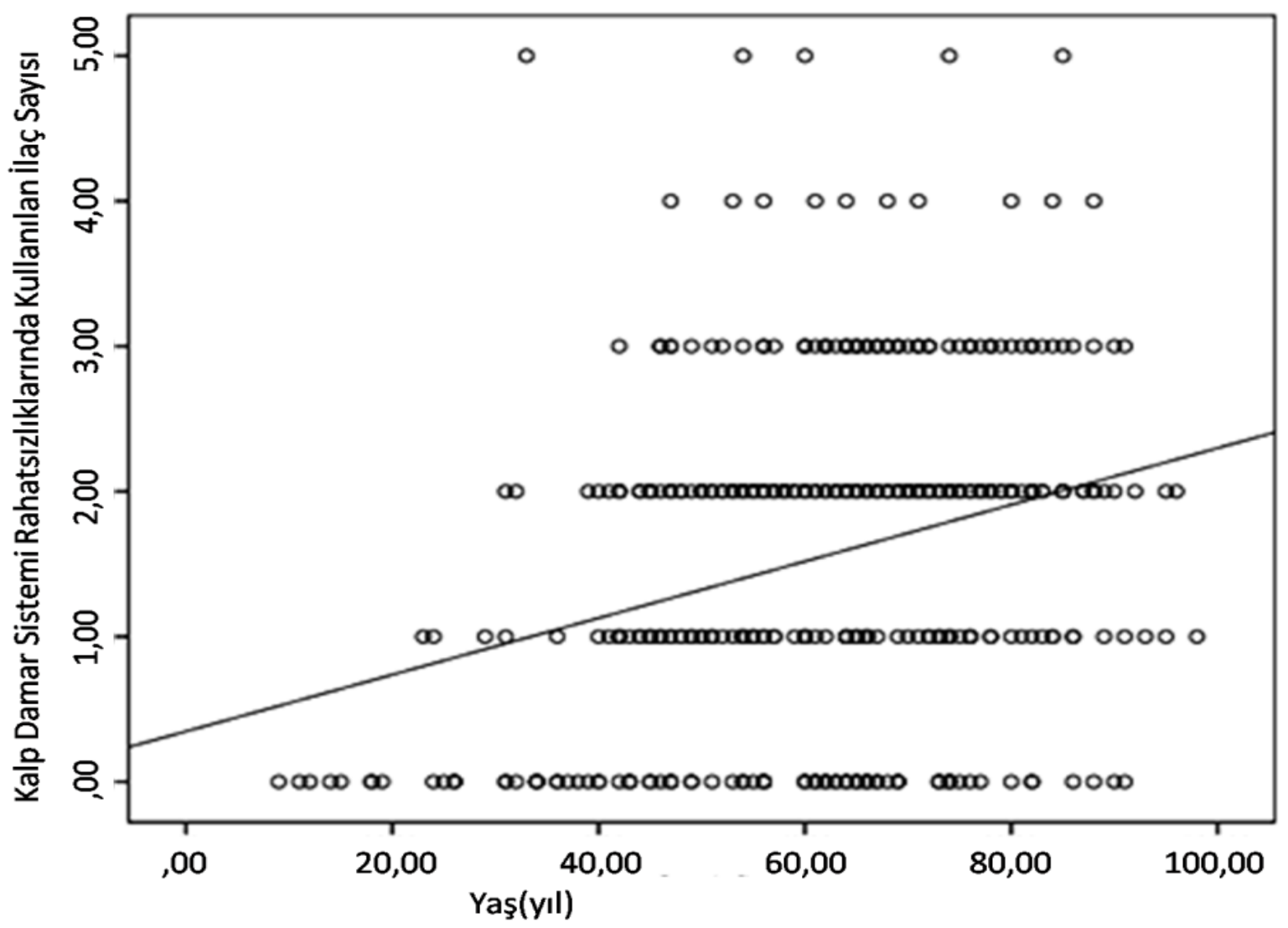

Şekil 2. Kalp damar sistemi rahatsızlıklarında kullanılan ilaç sayısının yaş ile korelasyonu

Kas iskelet sistemi rahatsılıklarında kullanılan ilaç sayısı negatif yönlü ve zayıf bir korelasyon göstermiştir $(p<0,001, r=-0,175)$, diüretik sayısı pozitif yönlü ve zayıf bir korelasyon göstermiştir
( $\mathrm{p}<0,001, \mathrm{r}=0,159)$, angiotensin II reseptör blokeri sayısı pozitif yönlü ve zayıf bir korelasyon göstermiştir $(\mathrm{p}<0,001, \mathrm{r}=0,263)$ (Tablo 5). 


\begin{tabular}{|l|c|c|}
\hline \multicolumn{2}{|l|}{ Tablo 5. Hasta başına raporlanan ilaçların yaş ile korelasyonu } \\
\hline \multicolumn{2}{|c|}{} \\
\cline { 2 - 3 } & r & p \\
\hline Hasta başına rapor sayısı & $-0,043$ & 0,465 \\
\hline Hasta başına raporlanan etken madde sayısı & 0,032 & 0,592 \\
\hline Rapor başına kullanılan ilaç sayısı & 0,087 & 0,144 \\
\hline $\begin{array}{l}\text { Hasta başına kalp damar sistemi rahatsızlıklarında kullanılan } \\
\text { ilaç sayısı }\end{array}$ & 0,266 & $<\mathbf{0 , 0 0 1}$ \\
\hline $\begin{array}{l}\text { Hasta başına sindirim sistemi rahatsılıklarında kullanılan ilaç } \\
\text { sayısı }\end{array}$ & $-0,025$ & 0,592 \\
\hline Hasta başına sinir sistemi rahatsılıklarında kullanılan ilaç sayıs1 & 0,084 & 0,075 \\
\hline $\begin{array}{l}\text { Hasta başına kas iskelet sistemi rahatsızlıklarında kullanılan ilaç } \\
\text { sayısı }\end{array}$ & $-0,175$ & $<\mathbf{0 , 0 0 1}$ \\
\hline $\begin{array}{l}\text { Hasta başına kan ve kan yapıcı organ hastalıklarında kullanılan } \\
\text { ilaç sayısı }\end{array}$ & $-0,055$ & 0,251 \\
\hline Hasta başına kullanılan diüretik ilaç sayısı & 0,159 & $\mathbf{0 , 0 0 1}$ \\
\hline Hasta başına kullanılan angiotensin II reseptör blokeri sayısı & 0,263 & $<\mathbf{0 , 0 0 1}$ \\
\hline $\begin{array}{l}\text { Hasta başına kullanılan lipid metabolizması düzenleyici ilaç } \\
\text { sayısı }\end{array}$ & $-0,043$ & 0,365 \\
\hline Hasta başına kullanılan oral antidiyabetik ilaç sayısı & 0,015 & 0,746 \\
\hline
\end{tabular}

\section{TARTIŞMA}

Birinci basamaktaki ilaç raporları daha önce irdelenmemiş bir konudur. $\mathrm{Bu}$ yüzden çalışma verilerinin literatür verileri ile kıyaslanması mümkün olmamıştır. $\mathrm{Bu}$ hem kuvvet hem de limitasyon olarak değerlendirilebilir.

İlaç raporu düzenlemek, aile hekiminin koruyucu ve tedavi edici sağlık hizmeti sunmak gibi temel görevlerininiçine girmeyen bir yetki ve inisiyatiftir. ${ }^{4,5}$ Aile hekimi sertifikasına sahip pratisyen hekimlerin ilaç raporu düzenleme yetkisi bulunmamaktadır. Aile hekimliği uzmanları ise sağlık uygulama tebliği hükümleri doğrultusunda uzman hekim raporu düzenleyebilmektedirler, bu da kronik hastalık takibinde kendilerine ve hastalarına avantaj sağlamaktadır. Verilerimize göre kişi başına düşen rapor sayısı ve rapordaki etken madde sayısı ortanca değerinin birden fazla olması, hasta ile iletişim süreci devam ettikçe çok sayıda vücut sisteminin kontrol altında tutulabileceğini göstermektedir.
Aile hekimliği uzmanları özel uzmanlık dalı gerektirmeyen diyabet mellitus, hipertansiyon gibi bir takım kronik hastalıklara özel ilaç raporlarını düzenleyebilmektedirler ancak astım, hiperlipidemi gibi hastalıkların tedavisinde kullanılan bazı ilaçların raporlarını düzenleyememektedirler. Verilerimize göre antihipertansif ve/veya antidiyabetik ilaçlar hastaların önemli bir kısmına raporlanmıştır.

Sağlık sisteminin iskeletini birinci basamak sağlık hizmetleri oluşturduğunda daha az maliyetle daha başarılı sağlık çıktıları elde etmek mümkündür. Birinci basamakta iş gücü niteliğini arttıracak ve hizmet kalitesini yükseltecek evrensel aile hekimliği ilkeleri ve görev tanımı ile uyumlu uygulamaların çoğaltılması gerekmektedir. ${ }^{6}$ İlaç raporu düzenlemek, bilgi birikimi ve uzmanlık gerektirdiğinden, bu hizmet kalitesini arttıracak uygulamalardan biri olarak değerlendirilebilir. Katılımcılarımızın büyük bir kısmının ilaç raporlanması amaciyla kardiyoloji, dahiliye, endokrinoloji vs. hekimlerine gitmesine gerek 
kalmadığı görülmüştür. Birinci basamakta kronik, yineleyen ya da terminal dönem rahatsızlıkları olan hastaların sürekli bakım sorumluluğu sürekli erişimle üstlenilmektedir. ${ }^{7}$ Kronik hastalıkların tedavi süreci, sürekli izlem ve yakın ilgi gerektirmektedir. İzlemdeki devamlılık beraberinde olası yanlışlıklar veya aksaklıkları da yok edebilmektedir. Herhangi bir nedenden ötürü aile sağlığı merkezine başvuru yapan bir hastanın raporunun sona erip ermediği, ilaç bitiş süresi ile rapor süresinin örtüşüp örtüşmediği, ilaca verilen yanıta göre yeni rapor düzenlenip düzenlenmemesi gerektiğinin değerlendirmesi yapılabilmektedir. Kronik hastalıklarda sağlanan bu kontrol; hastaya faydalı olduğu gibi ikinci ve üçüncü basamaktaki ekonomik kaybın ve işgücü kaybının azaltılmasına da yardımcı olmaktadır. ${ }^{8}$

Aile hekimliği uzmanlarının ihtisas süresinde aldıkları multidisipliner eğitime istinaden, düzenleyebilecekleri ilaç raporları üzerindeki kısıtlamalar giderilmeli ve kronik hastalıkların tedavisinde, (özellikle diyabet, kronik obstrüktif akciğer hastalığı ve hiperlipidemide kullanılan pek çok ilacın) aile hekimliği uzmanı tarafından yazılması ve rapor çıkarılması sağlanmalıdır. Bu sayede aile hekimliği uzmanları, disiplinlerine uygun spesifik uygulamaları daha rahat yapabilecek bir konuma gelebilirler. ${ }^{9}$ Katılımcılarımıza düzenlenen ilaç raporlarında akciğer hastalıklarına ait yeterli veri görülmemesi bunun bir sonucudur. Oysaki sigara içiciliğinin yüksek oranlarda olduğu ülkemizde, akciğer hastalıklarının tedavi sürecinde birinci basamağın da aktif rol alması süreci kolaylaştırabilir. ${ }^{10,11}$

Başak'ın belirttiği üzere, kronik hastalıkların ve çoklu rahatsızlıkların yönetimi ve kontrolü, bireye sunulan bakımın koordinasyonu, hasta uyumunun arttırılması, yaşam tarzı değişiklikleri ve davranış değişikliği oluşturma gibi aile hekimliğinin doldurması beklenen sağlık hizmet sunumunda bazı temel bakım boşlukları mevcuttur. $^{12}$ İlaç raporu düzenleme yetkisinin genişletilmesi bu boşlukların bir kısmını doldurabilir.

\section{SONUÇ}

Birinci basamak uzmanının kronik hastalıklarının medikal izleminde düzenlediği raporlarla etkin rol aldığı görülmüştür. İlaç raporları birinci basamak hasta popülasyonunun ikinci ve üçüncü basamağ tercih etmesine engel olabilecek faktörlerdendir ve kronik izlemde sürekliliği arttırıp başarıya katkı sağlayabilir.

\section{KAYNAKLAR}

1. Bruin SR, Versnel N, Lemmens LC, et al. Comprehensive care programs for patients with multiple chronic conditions: a systematic literature review. Health Policy 2012;107(2): 108-45.

2. Cayir Y. Evde Sağlık Hizmetleri. TJFMPC 2020;14(1): 147-152. DOI: 10.21763/tjfmpc.693164

3. Asarcik Belediyesi internet sitesi. http://asarcik.bel.tr/sayfa.aspx?s=ilcemiz (Erişim 02.01.2019)

4. Aile hekimliği uygulama yönetmeliği. Resmi Gazete Tarihi: 25.01.2013 Resmi Gazete Sayıs1: 28539

5. Yardımcı Y, Akbıyık D. İ, Aypak C, Yıkılkan H, Görpelioğlu S. Türkiye'de aile hekimliği uygulaması ve sözleşmeli aile hekimliği uzmanlık eğitimi. TJFMPC 2016;10(2):81-90. DOI: $10.5455 /$ tjfmpc. 207946

6. Akman M. Türkiye'de birinci basamağın gücü. Türk Aile Hek Derg 2014;18(2):70-8.

7. McWhinney I. R. Primary care: core values. Core values in a changing world. BMJ 1998;316:1807-9.

8. Eser U. Kronik hastalıklar ve aile hekimliği. Smyrna Tip Dergisi 2015;2:55-7.

9. Türkiye aile hekimleri uzmanlık derneği (TAHUD) tarafından T.C. Sağlık Bakanlığı'na verilmek üzere hazırlanan kısa rapor. Türkiye aile hekimleri uzmanlık derneği. 11 Ekim 2018. https://www.tahud.org.tr/file/2aa996d6eb09-4020-aed15874d5464767/Tam\%20Rapor\%20.pdf (Erişim $01.09 .2020)$

10. Üzer F. Devlet hastanesi çalışanlarının sigara kullanma alışkanlıklarına bakış. Türk Aile Hek Derg 2018;22(2):92-9.

11. Topçu S, Akın E, Ulukol B, Orhon FŞ, Başkan S. Sigaranın çocuğa etkileri konusunda ailelerin farkındalıkları, tutum ve davranışları. TJFMPC 2018;12(1):35-42. DOI: 10.21763/tjfmpc.399918

12. Başak O. Bir disiplin olarak aile hekimliğinin ülkemizdeki gelişim özellikleri. Türk Aile Hek Derg 2013;17(1):29-36. 